
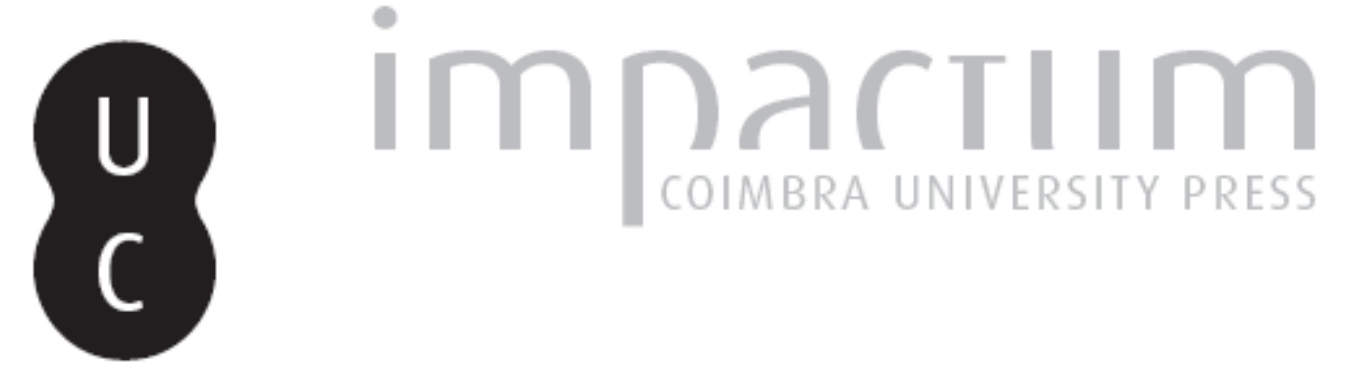

Refugiados em Portugal: fronteira e vigilância no tempo da Guerra Civil de Espanha (19361939)
Autor(es):
Faria, Fábio Alexandre
Publicado por: Imprensa da Universidade de Coimbra
URL persistente:
URI:http://hdl.handle.net/10316.2/43239
DOI:
DOI:https://doi.org/10.14195/0870-4147_48_3

Accessed : $\quad$ 26-Apr-2023 09:22:37

A navegação consulta e descarregamento dos títulos inseridos nas Bibliotecas Digitais UC Digitalis, UC Pombalina e UC Impactum, pressupõem a aceitação plena e sem reservas dos Termos e Condições de Uso destas Bibliotecas Digitais, disponíveis em https://digitalis.uc.pt/pt-pt/termos.

Conforme exposto nos referidos Termos e Condições de Uso, o descarregamento de títulos de acesso restrito requer uma licença válida de autorização devendo o utilizador aceder ao(s) documento(s) a partir de um endereço de IP da instituição detentora da supramencionada licença.

Ao utilizador é apenas permitido o descarregamento para uso pessoal, pelo que o emprego do(s) título(s) descarregado(s) para outro fim, designadamente comercial, carece de autorização do respetivo autor ou editor da obra.

Na medida em que todas as obras da UC Digitalis se encontram protegidas pelo Código do Direito de Autor e Direitos Conexos e demais legislação aplicável, toda a cópia, parcial ou total, deste documento, nos casos em que é legalmente admitida, deverá conter ou fazer-se acompanhar por este aviso.

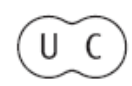




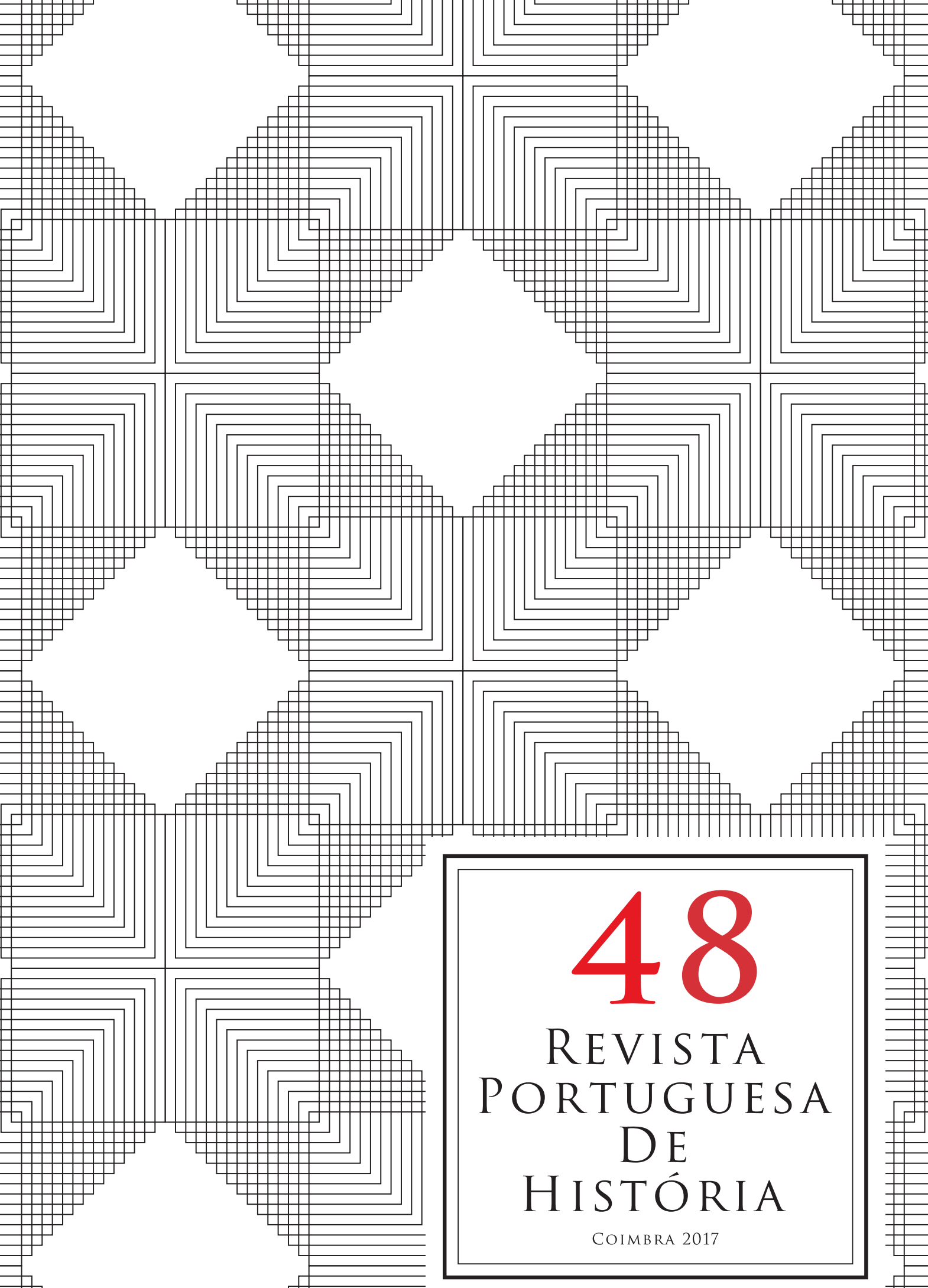




\title{
Refugiados em Portugal. Fronteira e vigilância no tempo da Guerra Civil de Espanha (1936-1939)
}

\author{
Refugees in Portugal. Frontier and vigilance at the time \\ of Spanish Civil War (1936-1939)
}

\author{
FÁbio AleXANDRe Faria ${ }^{1}$ \\ Instituto Universitário de Lisboa (ISCTE-IUL), \\ Centro de Investigação e Estudos de Sociologia (CIES-IUL) \\ fabiofaria19@hotmail.com
}

Texto recebido em/Text submitted on: 31/01/2017

Texto aprovado em/Text approved on: 26/05/2017

Resumo:

Em contexto de ditadura, instituída oficialmente em 1933, regime autoritário e receoso do contacto com o exterior, o poder viu-se confrontado com a entrada massiva de refugiados, consequência da Guerra Civil de Espanha (1936-1939) e da II Guerra Mundial (1939-1945).

Com o início da Guerra Civil em Espanha, a 18 de julho de 1936, milhares de espanhóis, civis e militares, republicanos e franquistas, tentaram abandonar o país receando os perigos decorrentes do conflito. Portugal, pela sua proximidade geográfica, foi um país especialmente procurado pelos foragidos espanhóis como lugar de refúgio.

Dada a natureza do regime, foi prioridade controlar e vigiar a entrada destes estrangeiros no país. Com esse objetivo, os postos fronteiriços de vigilância foram reforçados, especialmente nos primeiros meses do conflito espanhol, e estreitou-se a colaboração entre as diversas forças policiais portuguesas.

Não obstante estas medidas, muitos espanhóis passaram a fronteira portuguesa clandestinamente e refugiaram-se no país, contando com o auxílio de portugueses e de outros espanhóis residentes em Portugal.

Explora-se, neste artigo, a presença destes refugiados em Portugal e dá-se particular destaque à vigilância das fronteiras e às operações policiais desenvolvidas na região norte do país nos primeiros meses da Guerra Civil de Espanha, no sentido de controlar este fluxo.

Palavras-chave:

Refugiados, Guerra Civil de Espanha, Estado Novo, Espanhóis.

${ }^{1}$ Bolseiro de Doutoramento da Fundação para a Ciência e Tecnologia (Referência SFRH/ BD711483/2016). Doutorando em História Moderna e Contemporânea - Defesa e Relações Internacionais no ISCTE - Instituto Universitário de Lisboa. O autor agradece à Professora Doutora Maria João Vaz (ISCTE - Instituto Universitário de Lisboa) pela partilha de conhecimentos e por todas as sugestões apresentadas. 
Abstract:

In dictatorship context, officially established in 1933, authoritarian regime and afraid of contact with the outside, the rulers were faced with the massive influx of refugees from the Spanish Civil War (1936-1939) and World War II (1939-1945).

With the outbreak of the Spanish Civil War on July 18, 1936, thousands of Spanish, civilians and military, republicans and franquistas, tried to leave the country fearing the dangers arising from the conflict. Portugal, because of its geographical proximity, was a country especially sought by Spanish fugitives as a place of refuge.

Given the nature of the regime, it was priority to control and monitor the entry of these foreigners into the country. To this end, border surveillance posts were strengthened, especially in the first months of the Spanish conflict, and close collaboration was developed between the various Portuguese police forces.

Despite these measures, many Spanish crossed the Portuguese border clandestinely and took refuge in the country, counting on the help of Portuguese and other Spanish residing in Portugal.

This article explores the presence of these refugees in Portugal and highlights the border surveillance and police operations carried out in the north of the country in the early months of the Spanish Civil War to control this flow.

Keywords:

Refugees, Spanish Civil War, Estado Novo, Spanish. 


\section{Introdução}

Inscrito no século dos fascismos, o Estado Novo é geralmente caracterizado como sendo um regime autoritário, conservador, antiparlamentar, antidemocrático e antiliberal ${ }^{2}$, distinguindo-se, contudo, de outros movimentos autoritários da época, como o nazismo de Adolf Hitler e o fascismo de Benito Mussolini, «não só pela origem histórica, mas também ideológica e politicamente, tanto na sua política interna como na sua política externa, conseguindo por isso mesmo sobreviver à derrocada de ambos após a derrota na II Guerra Mundial $»^{3}$, conflito em relação ao qual Portugal se declarou como não beligerante.

Mas o salazarismo partilha um vasto conjunto de características com estes regimes totalitários, bem como com outros regimes de cariz próximo, como foi o caso do franquismo, como salienta Fernando Rosas ${ }^{4}$, a respeito da tentativa dos Estados de moldarem os súbditos aos seus ideais, fazendo uso de órgãos desenvolvidos especificamente para tal, ou António Costa Pinto, quando se debruça sobre a composição das elites ministeriais salazarista e franquista, considerando que existiu uma similaridade, embora admita algumas diferenças ${ }^{5}$. Um outro aspeto comum a estes regimes totalitários prendeu-se com a constante preocupação com a segurança do Estado, elemento central para a própria manutenção dos regimes, que se traduziu na criação de uma polícia política. No caso português, foi criada, em 1933, a Polícia de Vigilância e Defesa do Estado (PVDE), transformada na Polícia Internacional de Defesa do Estado, após o final da II Guerra Mundial.

A PVDE, subordinada ao Ministério do Interior, foi chefiada pelo capitão Agostinho Lourenço e tinha como principais competências a vigilância e o controlo de estrangeiros em Portugal, conforme consta do decreto-lei n. ${ }^{\circ} 22.992$, de 29 de agosto de 1933, que a institucionalizou. Desta forma, cabia à PVDE «[...] Impedir a entrada no País de estrangeiros indocumentados ou indesejáveis; Organizar o registo geral e cadastro dos estrangeiros com residência permanente ou eventual no País; Exercer sobre os estrangeiros que residam ou transitem pelo País a ação policial necessária $[\ldots] »^{6}$.

${ }^{2}$ Yves Léonard, Salazarismo e Fascismo, Mem Martins, Editorial Inquérito, 1996.

${ }^{3}$ Manuel Braga da Cruz, O Partido e o Estado no Salazarismo, Lisboa, Editorial Presença, 1988.

${ }^{4}$ Fernando Rosas, "O salazarismo e o homem novo: ensaio sobre o Estado Novo e a questão do totalitarismo", Análise Social, Vol. XXXV (157), 2001, p. 1031-1054.

${ }^{5}$ António Costa Pinto, "O império do professor: Salazar e a elite ministerial do Estado Novo (1933-1945)”, Análise Social, vol. XXXV (157), 2000, p. 1-22.

${ }^{6}$ Diário do Governo, I Série, n. ${ }^{\circ}$ 195, 29 de agosto de 1933, p. 1584. 
Nos anos imediatamente a seguir à sua constituição, a PVDE confrontou-se com diversos episódios, motivados por acontecimentos internacionais, que colocaram à prova o desempenho destas funções, de que são exemplo os fluxos de refugiados que procuraram abrigo em Portugal, primeiro em consequência das perseguições a setores da população existente no seio dos totalitarismos europeus, demonstrando o movimento de fronteiras que a partir de 1932-1933 a entrada de estrangeiros se intensifica, depois devido à Guerra Civil de Espanha (1936-1939) e, por último, por motivo da II Guerra Mundial e das perseguições nazis (1939-1945). De facto, no contexto do Estado Novo, regime autoritário e autocrata, que receava o contacto com o exterior e a perniciosa influência que tal poderia ter na sociedade portuguesa, os governantes viram-se confrontados com a entrada massiva de refugiados, um dos principais problemas com que Salazar e as autoridades portugueses tiveram de lidar durante este período.

A centralidade desta questão levou o próprio Agostinho Lourenço a atribuir «enorme importância a uma boa fiscalização das fronteiras e ao controlo dos estrangeiros, como meios fundamentais à defesa da ordem» ${ }^{7}$. Devido à complexidade do problema, a PVDE não atuou sozinha e contou com uma colaboração bastante próxima de outras forças policiais, como foi o caso da Guarda Nacional Republicana (GNR), da Polícia de Segurança Pública (PSP) e da Guarda Fiscal (GF), esta última diretamente responsável pelo controlo e vigilância das fronteiras.

Este artigo centra-se, portanto, na análise do papel desempenhado pelas forças policiais portuguesas perante a chegada de refugiados ao território nacional que procuravam escapar da Guerra Civil de Espanha, sendo dado particular enfoque às ações de vigilância na fronteira luso-espanhola.

\section{Conceito de Refugiado: uma abordagem histórica}

A consulta de dicionários editados em diferentes épocas permite-nos conhecer a evolução que um determinado termo teve ao longo do tempo. O conceito de refugiado parece ter sido um conceito que surgiu apenas no século $\mathrm{XX}$, uma vez que não consta dos dicionários do século XIX consultados, de que são exemplo os da autoria de António de Morais Silva, havendo apenas uma pequena

${ }^{7}$ Maria da Conceição Ribeiro, A Polícia Política no Estado Novo (1926-1945). Génese, funções e atuações da PVDE, Dissertação de Mestrado na Universidade Nova de Lisboa Faculdade de Ciências Sociais e Humanas, Lisboa, 1992, policopiado. 
referência ao termo enquanto particípio passado do verbo refugiar ${ }^{8}$. Ressalve-se que, no dicionário de 1823, refúgio surge identificado como «asilo que busca quem foge ou vem perseguido», definição que se aproxima da realidade vivida pelos refugiados da Guerra Civil de Espanha de 1936-1939.

Como refere Carolina Henriques Pereira, foi efetivamente a partir da adoção da Convenção das Nações Unidas relativamente ao Estatuto dos Refugiados, em 1951, que se verificou o despontar de uma maior preocupação a nível mundial relativamente ao problema dos refugiados ${ }^{9}$. No entanto, como qualquer conflito de grande escala, a I Guerra Mundial (1914-1918) já havia produzido um assinalável deslocamento de pessoas, quer dentro dos próprios países, quer entre os Estados, agravando os problemas destes para lidar com questões humanitárias. Cite-se, a título de exemplo, a preocupação do Governador Civil de Leiria, no final de 1917, com a necessidade de fazer sair do país os alemães que se encontravam concentrados nas Caldas da Rainha, alegando as medíocres condições de alojamento e as dificuldades de abastecimento do concelho, em virtude da escassez de géneros registada ${ }^{10}$, não se devendo esquecer, contudo, que Portugal era beligerante e a Alemanha era inimiga.

Na sequência deste conflito foram envidados esforços por parte da Sociedade das Nações, constituída no final da guerra, no sentido de se definirem as principais responsabilidades dos Estados relativamente aos refugiados. Nesse sentido, a 28 de outubro de 1933, ano em que se instituía o auto-denominado Estado Novo, surgiu a Convenção sobre o Estatuto Internacional dos Refugiados. Esta Convenção, antecedida por outros acordos intergovernamentais, nomeadamente de 5 de Julho de 1922, de 31 de maio de 1924, de 12 de maio de 1926 e de 30 de junho de 1928, foi inicialmente assinada pela França, a Bélgica, a Bulgária, a Noruega e o Egito ${ }^{11}$. Segundo o estipulado na Convenção, esta aplicava-se aos refugiados russos, arménios e assimilados e garantia-lhes o acesso a passaportes

${ }^{8}$ António de Morais Silva, Dicionário da Língua Portuguesa, Tomo II, Lisboa, Tipografia de António José da Rocha, 1858 (6. ${ }^{\mathrm{a}}$ ed.); António de Morais Silva, Dicionário da Língua Portuguesa recopilado de todos os impressos até ao presente, tomo II, Tipografia de M. P. de Lacerda, 1823 (3. ${ }^{a}$ ed.).

${ }^{9}$ Carolina Henriques Pereira, "A presença de refugiados nas Caldas da Rainha durante a Segunda Guerra Mundial (1939-1945)”, Caderno de Estudos Leirienses, 8 (2016), p. 323-339.

${ }^{10}$ Instituto Arquivos Nacionais/Torre do Tombo (Lisboa), Ministério do Interior, Maço 78, Livro $67 / 68$, n. $^{\circ} 963$.

${ }^{11}$ Texto da Convenção disponível em https://www.wdl.org/pt/item/11580/ (consultado em 2016/12/21). 
Nansen ${ }^{12}$. A Convenção de 1933 procurava abranger uma multiplicidade de áreas relativamente ao apoio a dar aos refugiados, de entre as quais se destacavam a condição jurídica, a área laboral, o plano da assistência e da providência, a instrução e educação e o regime fiscal.

Uma das principais preocupações dos signatários passava por garantir aos refugiados os mesmos direitos e privilégios de que usufruíam os cidadãos nacionais, tal como consta, por exemplo, do artigo $6 .^{\circ}$, referente à condição jurídica. Verifica-se, ao longo do texto da Convenção, que os indivíduos contemplados pela mesma surgem sempre identificados pelo termo "refugiados", e não por qualquer outra terminologia similar, o que demonstra que este termo já se encontrava internacionalmente em voga naquela época. Estipulava-se também a organização de um comité central ou de vários comités para os refugiados em cada um dos países signatários, devendo as disposições dos acordos internacionais anteriores permanecer em vigor, no caso de serem compatíveis com a Convenção que à data se assinava. Saliente-se ainda que todos os Estados signatários colocaram reservas à assinatura do texto internacional, destacando-se o governo egípcio que, dando primazia à segurança interna do país, concedia às autoridades egípcias o direito de expulsarem os refugiados a qualquer momento quando estes colocassem em risco a segurança pública.

Observa-se que, apesar de consagrar a proibição de expulsão dos refugiados para países onde pudessem vir a ser alvo de perseguição, a eficácia desta Convenção ficou reduzida pelo facto de ter sido ratificada por um pequeno número de países, os quais ainda colocaram algumas reservas ${ }^{13}$. Efetivamente, até março de 1936, de entre os vinte e três países participantes na reunião, apenas os cinco Estados mencionados acima haviam ratificado esta Convenção ${ }^{14}$.

Em 1936, em virtude do incremento da perseguição nazi a cidadãos residentes na Alemanha, e também porque a Convenção de 1933 não contemplava os refugiados alemães, houve a necessidade de se alterar a situação. Para tal, teve lugar uma reunião internacional em julho desse ano. No acordo resultante desse encontro considerava-se que um refugiado alemão era qualquer indivíduo que

${ }^{12}$ A denominação atribuída a estes passaportes vem na sequência da nomeação do norueguês Friedtjof Nansen para desempenhar o importante cargo de primeiro Alto-Comissário para os Refugiados, em 1921.

${ }^{13}$ Leonor Amaro Gonçalves Vieira, Actos de perseguição religiosa e proteção dos refugiados na União Europeia - análise do Acórdão do Tribunal de Justiça Bundesrepublik Deutschland contra Y e Z, Dissertação de Mestrado na Universidade do Minho - Escola de Direito, 2014, policopiado.

${ }^{14}$ Ansgar Schaefer, Portugal e os refugiados judeus provenientes do território alemão, Coimbra, Imprensa da Universidade de Coimbra, 2014. 
se encontrasse num país de acolhimento, que apenas possuísse a nacionalidade alemã e que não usufruísse da proteção do governo germânico. $\mathrm{O}$ artigo 4. ${ }^{\circ}$, respeitante à questão da segurança, assegurava que nenhum refugiado seria expulso ou colocado na fronteira, processo designado por refoulement ${ }^{15}$.

Este acordo não satisfez totalmente as necessidades inerentes à situação de refugiado, constantemente aumentadas pelo agravamento da situação internacional, pelo que os Estados concordaram na urgência em se realizar um novo encontro internacional, o qual teve lugar em fevereiro de 1938, contudo, diferindo pouco do seu antecessor. Outra das razões que levou os governos mundiais a mostrarem-se unânimes quanto à necessidade de se organizar uma nova Convenção prendeu-se com a pouca adesão ao acordo de 1936, algo que também se verificou relativamente aos pactos anteriores. Neste aspeto, Portugal assumiu um papel de destaque.

De facto, os diferentes regimes políticos portugueses que vigoraram ao longo das décadas de 1920 e de 1930 (I República, Ditadura Militar e Estado Novo) mostraram-se pouco ativos relativamente aos acordos internacionais respeitantes aos refugiados, provavelmente dada a forte instabilidade governativa interna. Assim, como assinala Susana Chalante, Portugal apenas deu o seu parecer positivo relativamente à concessão de bilhetes de identidade a refugiados russos e arménios e rubricou as recomendações respeitantes aos títulos de identidade e de viagem ${ }^{16}$. Apesar de o número de indivíduos que procuravam abrigo em Portugal ter aumentado consideravelmente ao longo da década de 1930, o Estado Novo parece ter-se mostrado pouco preocupado em desenvolver legislação específica relativa aos refugiados, considerando o Governo que, caso tivessem entrado no país de forma legal e possuíssem documentos de identificação válidos, estes deveriam ser tratados da mesma forma que os restantes estrangeiros ${ }^{17}$. Saliente-se, contudo, que conforme se avança na década, o regime salazarista parece mostrar-se mais atento à questão dos refugiados e, exemplo disso, é o facto de ter decidido fazer-se representar na conferência de fevereiro de 1938, algo que nunca acontecera nos encontros intergovernamentais anteriores ${ }^{18}$.

${ }^{15}$ Ansgar Schaefer, Portugal e os refugiados..., cit., p. 32 e 33.

${ }^{16}$ Susana Chalante, "O discurso do Estado salazarista perante o «indesejável» (1933-1939)", Análise Social, 198 (2011), p. 41-63.

${ }^{17}$ Arquivo do Ministério dos Negócios Estrangeiros, Ofício de F. de Andrade, 3. ${ }^{\circ}$ P., A. 28 M. 49 “REFUGIADOS”, Pasta: Office Internacional NANSEN, Passaportes e títulos de identificação dos refugiados, 23/10/1935.

${ }^{18}$ Ansgar Schaefer, Portugal e os refugiados..., cit., p. 43. 
Os acordos internacionais que iam surgindo a partir da I Guerra Mundial eram elucidativos do que se entendia por refugiado naquela época, uma vez que uma das principais preocupações demonstradas nesses acordos era garantir abrigo a quem se deslocasse em busca de asilo e proteção. Como consta dos dicionários do século XX, entendia-se exatamente por refugiado «aquele que se refugiou», ou seja, aquele que se deslocou para «esconder-se ou abrigar-se; expatriar-se; procurar abrigo ou proteção» ${ }^{19}$.

No mesmo sentido, Agostinho de Campos define refúgio como um «lugar para onde alguém se retira para estar seguro; auxílio» ${ }^{20}$. Idêntica significação apresentam Augusto Moreno, José da Silva Bandeira e J. T. da Silva Bastos ${ }^{21}$, sendo também comum a todos estes autores a definição do verbo refugiar-se. Este último é quem apresenta uma definição mais completa, considerando que este termo pode significar «retirar-se; esconder-se ou abrigar-se; expatriar-se; procurar abrigo, proteção».

Observamos que não existiam grandes diferenças na definição destes conceitos no que concerne aos séculos XIX e XX, sendo que já no século XIX se identificava refúgio como espaço de proteção e de abrigo procurado por quem se encontrava fugido. A principal diferença reside no facto de o termo refugiado não ser utilizado no vocabulário do século XIX, parecendo ser um conceito que surge no século seguinte.

\section{Movimentos populacionais em contexto de guerra: o caso da Guerra Civil de Espanha}

Os conflitos bélicos são, indubitavelmente, causadores de grandes movimentos populacionais, sejam confrontos envolvendo dois ou mais Estados ou guerras dentro do mesmo país opondo forças distintas. Cite-se, a título de exemplo para o século XX, os casos da I Guerra Mundial e da II Guerra Mundial, ambas geradoras de um enorme número de refugiados que percorreram não só a Europa, como também todo o mundo em busca de abrigo. No que respeita à II Guerra Mundial, esse movimento agravou-se ainda mais em consequência

${ }^{19}$ Cândido de Figueiredo, Grande Dicionário da Lingua Portuguesa, volume II, Lisboa, Livraria Bertrand, 1982 (15. a ed. [1913]).

${ }^{20}$ Agostinho de Campos, Dicionário de Língua Portuguesa para uso das escolas, Lisboa, Livraria Bertrand, 1938.

${ }^{21}$ Augusto Moreno, Dicionário Elementar da Língua Portuguesa, Porto, Editora Educação Nacional, 1934; José da Silva Bandeira, Dicionário de Sinónimos da Lingua Portuguesa, Coimbra, Tipografia da Gráfica de Coimbra, 1931; J. T. da Silva Bastos, Dicionário Etimológico, Prosódico e Ortográfico da Lingua Portuguesa, Lisboa, Parceria António Maria Pereira, 1928. 
da perseguição anti-semita levada a cabo pelo nazismo alemão, a que se deve acrescentar, seguramente, os números resultantes da repressão desenvolvida por outros regimes totalitários, como o fascismo italiano e o comunismo estalinista. No interregno entre estes dois grandes conflitos mundiais teve lugar a Guerra Civil de Espanha, geralmente considerada como a antecâmara da II Grande Guerra.

Nos últimos 30 anos, o tema da Guerra Civil de Espanha e do seu impacto em Portugal tem despertado o interesse de investigadores não só no domínio da História, mas também noutras Ciências Sociais, como a Antropologia. De entre os diversos autores e das várias abordagens desenvolvidas, destacam-se: do ponto de vista da política externa e das relações diplomáticas, Iva Delgado e César Oliveira; segundo uma abordagem política e ideológica, Manuel Loff; sob a perspetiva da relação com a Igreja Católica, Valentim Alexandre; do ponto de vista da presença de refugiados espanhóis nas zonas raianas portuguesas e das solidariedades fronteiriças, Dulce Simões, João Urbano Pires, Maria Fernanda Candeias e Paula Godinho, os três primeiros sobre a zona alentejana e a última para o caso de Cambedo da Raia (Chaves) ${ }^{22}$.

Iniciado a 18 de julho de 1936, pelas mãos de Francisco Franco, que se opunha ao regime republicano vitorioso das eleições espanholas de fevereiro desse mesmo ano, este conflito foi responsável pela deslocação de inúmeras pessoas para Portugal, dada a proximidade geográfica entre ambos os territórios.

Com efeito, logo desde os primeiros dias imediatamente a seguir ao deflagrar do conflito, as fronteiras portuguesas viram-se assaltadas por um sem número de indivíduos que tentavam escapar ao conflito, o que, naturalmente, dificultou a atuação das forças policiais. Facilitada pela proximidade com Portugal, a

${ }^{22}$ Iva Delgado, Portugal e a Guerra Civil de Espanha, s.1., Europa-América, 1980; César Oliveira, Salazar e a Guerra Civil de Espanha, Lisboa, O Jornal, 1987; Manuel Loff, Salazarismo e Franquismo na Época de Hitler (1936-1942). Convergência política, preconceito ideológico e oportunidade histórica na redefinição internacional de Portugal e Espanha, Porto, Campo das Letras, 1996; Valentim Alexandre, O roubo das almas. Salazar, a Igreja e os totalitarismos (1930-1939), Lisboa, D. Quixote, 2006; Dulce Simões, Fronteira e Guerra Civil de Espanha. Dominação, resistência e usos da memória em Barrancos, Tese de Doutoramento, Lisboa, Faculdade de Ciências Sociais e Humanas da Universidade Nova de Lisboa, 2011; João Urbano Pires, A memória da Guerra Civil de Espanha no Baixo Alentejo, Dissertação de Mestrado, Lisboa, ISCTE - Instituto Universitário de Lisboa, 1997; Maria Fernanda Candeias, O Alentejo e a Guerra Civil de Espanha. Vigilância e fiscalização das povoações fronteiriças, Tese de Mestrado, Lisboa, Faculdade de Ciências Sociais e Humanas da Universidade Nova de Lisboa, 1997; Paula Godinho, Oír o galo cantar duas veces. Identificacións locais, culturas de marxes e construción de nacións na fronteira entre Portugal e Galicia, Ourense, Imprenta da Deputación, 2011. 
presença de espanhóis no país já era assinalável antes do início da Guerra Civil de Espanha, sobretudo durante a época balnear, atividade que será muito menos procurada com o início do conflito, como assinala Irene Vaquinhas para o caso da Figueira da Foz, lugar de eleição para os veraneantes do país vizinho ${ }^{23}$. De facto, contrariamente ao que seria expectável, o início do conflito, em vez de provocar um aumento, significou uma profunda diminuição do número de espanhóis que procuravam Portugal para lazer, sendo a sua maioria constituída por aqueles que tentavam entrar no país para escapar à guerra.

Se tivermos em conta as estatísticas elaboradas pela PVDE, em julho de 1939, verificamos que a comunidade estrangeira residente em Portugal nos anos que antecederam a Guerra Civil de Espanha era dominada pelos cidadãos de origem espanhola. Para o ano de 1934, a PVDE registava a entrada em Portugal de 34.317 espanhóis, a grande maioria por via terrestre, e a saída de 31.903 indivíduos. No ano seguinte, o número de espanhóis que davam entrada no país subiu ligeiramente para 35.677, tal como aumentou para 34.615 o número daqueles que deixavam o território. Em 1936, ano do despontar do conflito espanhol, a PVDE assinalava o decréscimo de espanhóis que haviam entrado em Portugal para 30.356, número que se aproximava bastante do correspondente aos espanhóis que abandonaram o país nesse mesmo ano (30.277). Nos dois anos seguintes é visível a redução significativa dos espanhóis que entraram em Portugal (16.160 em 1937 e 10.217 em 1938), sendo estes números suplantados em ambos os anos pela quantidade de indivíduos que deixaram o território (17.912 em 1937 e 10.879 em 1938). Esta presença de espanhóis em Portugal é tanto mais significativa se tivermos em consideração que, tal como consta do referido relatório, em 1934, 1935 e 1936 o seu número representava mais metade do total de estrangeiros que tinham entrado no país ${ }^{24}$.

No entanto, revela-se difícil descortinar se este relatório incluía também os espanhóis que entravam em Portugal clandestinamente em busca de refúgio ou apenas os que procuravam o país por motivos de turismo ou sazonalmente. No entender de César Oliveira, os indivíduos espanhóis que podem ser efetivamente considerados refugiados, uma vez que, procurando escapar a guerra estavam obrigados a abandonar as suas terras e posses, não foram considerados neste relatório. Este autor considera que «[...] os números adiantados pelo relatório

${ }^{23}$ Irene Vaquinhas, "Huyendo de la Guerra Civil: los refugiados españoles en Figueira da Foz (1936-1939)", Pensar com la historia desde el siglo XXI, Actas del XII Congresso de la Asociación de Historia Contemporánea, Madrid, Uma Ediciones, p. 4833-4854, 2015.

${ }^{24}$ Instituto Arquivos Nacionais/Torre do Tombo (Lisboa), Arquivo da PIDE/DGS, Direção dos Serviços de Estrangeiros e Fronteiras, Serviços Centrais, n. ${ }^{\circ}$ 9258, Relatório da Polícia de Vigilância e Defesa do Estado (1932-1938). 
da PVDE não tomaram em linha de conta os 1550 «refugiados vermelhos» levados a Tarragona pelo Niassa em outubro de 1936, nem certamente os «vermelhos» entregues às autoridades nacionalistas em agosto, setembro e outubro de 1936, embora devam comportar, eventualmente, os «refugiados vermelhos» escondidos em Portugal e capturados pela PVDE. ${ }^{25}$.

Se atentarmos nas estatísticas fornecidas pela PVDE no citado relatório sobre os estrangeiros expulsos de Portugal no período de 1931 a 1938, constatamos que o grande pico de expulsões teve lugar durante a Guerra Civil de Espanha e correspondeu a indivíduos de nacionalidade espanhola. Assim, em 1936 registou-se a expulsão de 126 espanhóis, aumentando para praticamente o dobro (246) no ano seguinte e decrescendo ligeiramente para 206 pessoas em 1938. Ao considerarmos apenas estes três anos, o número de espanhóis obrigados a sair do território português torna-se ainda mais significativo, visto que de um total de 202 estrangeiros expulsos em 1936, 126 eram espanhóis $(62,4 \%)$, dos 274 estrangeiros que foram obrigados a abandonar o país no ano seguinte, 89,8\% eram de nacionalidade espanhola, e os 206 espanhóis que foram expulsos em 1938 representaram 80,2\% de todos estrangeiros expulsos de Portugal nesse ano $(257)^{26}$.

Esta situação é comprovada pela consulta do Registo Geral de Presos da Polícia de Vigilância e Defesa do $\operatorname{Estado}^{27}$. De facto, a partir do despontar do conflito espanhol regista-se um incremento significativo no número de indivíduos espanhóis detidos pela PVDE. Observa-se que, nos meses em que houve uma maior afluência de espanhóis às fronteiras portuguesas, julho, agosto e setembro de 1936, muitos indivíduos foram capturados unicamente por motivo dos «acontecimentos revolucionários em Espanha», sendo estes maioritariamente originários da região de Zamora. A PVDE refere como outros motivos para as detenções: «refugiado comunista», «indocumentado e comunista», «refugiado de Espanha», «foragido político», «suspeito de pertencer à Frente Popular» e «suspeito de pertencer às milícias comunistas». Encontra-se em evidência nestas expressões uma das principais preocupações, se não mesmo a principal, do Estado Novo nesta altura: o receio de que o comunismo se difundisse em Portugal por intermédio dos refugiados. É de salientar também o emprego do termo «refugiado» por parte dos operacionais

${ }^{25}$ César Oliveira, Salazar..., cit., p. 179.

${ }^{26}$ Instituto Arquivos Nacionais/Torre do Tombo (Lisboa), Arquivo da PIDE/DGS, Direção dos Serviços de Estrangeiros e Fronteiras, Serviços Centrais, n. ${ }^{\circ}$ 9258, Relatório da Polícia de Vigilância e Defesa do Estado (1932-1938).

${ }^{27}$ Instituto Arquivos Nacionais/Torre do Tombo (Lisboa), Arquivo da PIDE/DGS, Registo Geral de Presos, Livros 18 a 33. 
da PVDE nestes registos, demonstrando entender que um refugiado naquele tempo era alguém que estava obrigado a abandonar a sua área de residência por motivo de guerra.

Estes foram os principais motivos apresentados pela PVDE para a detenção dos cidadãos espanhóis que chegavam às fronteiras portuguesas em busca de refúgio nos primeiros meses seguintes ao início da Guerra Civil de Espanha. Contudo, conforme se aproxima o fim de 1936, verifica-se que estas expressões vão sendo substituídas por outras não tão diretamente conectadas à situação espanhola, como «emigração clandestina e indocumentado», «suspeito» e «averiguações», observando-se ainda que, nos primeiros meses de 1937, aumentou o número de detidos espanhóis residentes em Portugal, pelo que não podem ser considerados refugiados. Efetivamente, com o despontar do conflito, parece ter existido um controlo mais apertado sobre os espanhóis que já viviam no país.

Segundo as informações constantes dos registos da PVDE, uma parte considerável dos refugiados capturados pela polícia política esteve detida no Forte de Caxias, ao passo que uma outra parte, menor, esteve presa no Aljube do Porto, sendo que a grande maioria destes detidos embarcou para Tarragona, localidade costeira próxima de Barcelona, a 10 de outubro de 1936. Cite-se, a título de exemplo, o caso de Claudino Gonzalez Rodriguez, espanhol natural de Pontevedra e residente em Lubian (Zamora), que foi detido pelas autoridades portuguesas em Chaves, a 26 de julho de 1936, por estar indocumentado e ser comunista. Após a detenção, foi conduzido para a Cadeia Civil da Comarca de Chaves, de onde foi transferido para a Delegação do Porto, a 11 de agosto de 1936. No dia seguinte passou para o Forte de Caxias, onde permaneceu até ser repatriado para Tarragona, em outubro desse ano ${ }^{28}$.

Segundo César Oliveira, o número de espanhóis que passaram pelo Forte de Caxias não excedeu os $250^{29}$, embora não apresente referências para tal afirmação, ao passo que Dulce Simões considera que a única estimativa conhecida que comprova a passagem de refugiados espanhóis pelo Forte corresponde a 82 indivíduos, aqueles que, em agosto de 1936, requeriam que lhes fossem fornecidas roupas interiores e calçado ${ }^{30}$. No entanto, de acordo com uma relação da existência de presos estrangeiros, produzida pela PVDE, encontravam-se, em 25 de setembro de 1936, 255 espanhóis no Forte de

${ }^{28}$ Instituto Arquivos Nacionais/Torre do Tombo (Lisboa), Arquivo da PIDE/DGS, Registo Geral de Presos, Livro 18, n. ${ }^{\circ} 3531$.

${ }^{29}$ César Oliveira, Salazar..., cit., p. 158.

${ }^{30}$ Dulce Simões, Barrancos na encruzilhada da Guerra Civil de Espanha. Memórias e Testemunhos, 1936, Lisboa, Edições Colibri/Câmara Municipal de Barrancos, 2007. 
Caxias. Em Bragança encontravam-se presos 99 espanhóis, em Elvas 61, em Moura 38, em Castelo Branco 18, em Chaves 12, em Barrancos 8, em Vilar Formoso 4, e em Valença e Campo Maior 1. Assim, de um total de 500 estrangeiros detidos em Portugal à data de 25 de Setembro de 1936, 496 eram de nacionalidade espanhola ${ }^{31}$.

Apesar de muitos refugiados terem sido capturados pelas forças policiais portuguesas e de vários outros terem sido entregues aos nacionalistas, como afirma, entre outros, Oliveira Marques, apontando que o número dessas entregas poderá ter ascendido aos milhares ${ }^{32}$, houve casos de espanhóis que, contando com ajuda de espanhóis residentes em Portugal e também de cidadãos portugueses, conseguiram evitar o regresso a Espanha. Manuel Reys Lindo, natural de Badajoz e residente no Barreiro, foi detido pela PVDE, a 6 de dezembro de 1936. Como motivo para a detenção, os operacionais da polícia política alegaram o facto de este ser suspeito de «dar guarida a refugiados espanhóis». No entanto, este espanhol, nascido em 1879, acabaria por ser restituído à liberdade exatamente um mês depois ${ }^{33}$. Diferente sorte teve Jacinto Vasquez Perez, espanhol de 27 anos, capturado pela PVDE a 13 de fevereiro de 1937. Segundo os registos da polícia política, Vasquez Perez, natural de Lovios e residente em Lisboa, foi preso por «suspeita de se dedicar a conseguir papéis de nacionalidades aos refugiados espanhóis», acabando por ser expulso pela fronteira de Elvas, em 7 de março de 1937. Pelo delito, ficou-lhe interdita a entrada no país ${ }^{34}$.

Estes dois casos exemplificam a solidariedade que houve para com os refugiados por parte de espanhóis já fixados em Portugal antes do despontar da guerra. Por seu turno, os portugueses não ficaram atrás na ajuda prestada aos fugitivos espanhóis. Esta realidade encontra-se estudada por Dulce Simões, especificamente sobre o caso dos refugiados em Barrancos, apresentando a autora diversos testemunhos que comprovam o auxílio dado pela população portuguesa àqueles que procuravam escapar da guerra em Espanha, de que é exemplo o que se segue: «Da guerra de Espanha só me recordo de ver muitos espanhóis aqui na rua, e recordo-me, porque o meu pai naquela época tinha

${ }^{31}$ Instituto Arquivos Nacionais/Torre do Tombo (Lisboa), Arquivo Oliveira Salazar, CO/IN-8C, caixa 332, pt. 1. Informações da PVDE sobre presos políticos portugueses e estrangeiros.

${ }^{32}$ Oliveira Marques, História de Portugal, Volume III, Lisboa, Palas Editores, 1986.

${ }^{33}$ Instituto Arquivos Nacionais/Torre do Tombo (Lisboa), Arquivo da PIDE/DGS, Registo Geral de Presos, Livro 28, n. ${ }^{\circ} 5419$.

${ }^{34}$ Instituto Arquivos Nacionais/Torre do Tombo (Lisboa), Arquivo da PIDE/DGS, Registo Geral de Presos, Livro 31, n. ${ }^{\circ} 6054$. 
um carro de mulas, de ir com ele à Coitadinha levar mantimentos ao campo de concentração que existia ali, onde estavam os espanhóis $[\ldots] \gg{ }^{35}$

Não foram só civis que prestaram auxílio aos refugiados espanhóis. Houve ainda militares portugueses que, levados pelo impulso humanitário, ajudaram os indivíduos que iam chegando às povoações portuguesas. Há a destacar, neste contexto, a atuação do Tenente da Guarda Fiscal António Augusto de Seixas, caso também já amplamente estudado por Dulce Simões. O Tenente Seixas é o exemplo mais conhecido de ajuda proporcionada aos refugiados espanhóis por um não civil, auxiliado pelos filhos Gentil e Amável de Valadares. Este oficial, que desempenhava o cargo de Tenente na secção de Safara (Alentejo), foi suspenso da sua atividade, em novembro de 1936, por dois meses e, posteriormente, passou à reforma. Augusto Seixas foi acusado de ter permitido a concentração de centenas de espanhóis na sua zona de vigilância, de ter ocultado a existência de campos de refugiados e de omitir o número exato de fugidos espanhóis que se encontravam naquela $z$ na $^{36}$. Porém, em dezembro de 1937, este castigo acabaria por ser levantado e António Augusto de Seixas regressaria à Guarda Fiscal ${ }^{37}$.

Esta penalização foi imposta por Salazar ao Tenente Seixas pouco tempo após o embarque de 1.445 refugiados espanhóis para Tarragona, contabilidade que consta do relatório do Capitão Ruy Pessoa, escrito a bordo do Niassa, embarcação que conduziu esses indivíduos àquela localidade espanhola ${ }^{38}$.

A 6 de outubro de 1936, o secretário-geral do Ministério dos Negócios Estrangeiros informava o ministro do Interior que o Governo espanhol havia aceitado a proposta portuguesa de repatriamento de refugiados. Segundo esta comunicação, o Governo português garantia, à sua custa, o repatriamento

${ }^{35}$ Dulce Simões, Frontera y Guerra Civil Española. Dominación, resistencia e usos de la memoria, Badajoz, Diputación de Badajoz/Departamento de Publicaciones, 2013. (Testemunho de Agostinho Gavino Carvalho, que, em criança, viajou com o pai à Herdade da Coitadinha. Entrevista concedida a Dulce Simões em janeiro de 2008. Tradução minha).

${ }^{36}$ Francisco Espinosa Maestre, "Barrancos, 1936: O caso do tenente Seixas e a aventura do Niassa" in Dulce Simões, Barrancos na encruzilhada da Guerra Civil de Espanha. Memórias e Testemunhos, 1936, Lisboa, Edições Colibri/Camara Municipal de Barrancos, 2007, p. 119-147. Ver também Dulce Simões, Frontera y Guerra Civil Española ..., cit., p. 219-284.

${ }^{37}$ Pedro Prostes da Fonseca, Contra as ordens de Salazar, Lisboa, Edições Matéria-prima, 2016.

${ }^{38}$ Arquivo José Pacheco Pereira, Relatório da PVDE de 16 de outubro de 1936, "Repatriação de extremistas espanhóis que se haviam refugiado em Portugal", disponível em https:// ephemerajpp.com/2011/12/31/policia-de-vigilancia-e-defesa-do-estado-repatriacao-de-extremistas-espanhois-que-se-haviam-refugiado-em-portugal-relatorio-16-de-outubro-de-1936/ (consultado em 2017/01/09). 
de todos os refugiados que desejassem ir para Tarragona, porto escolhido pelo Governo espanhol. Salazar alertava, contudo, que, caso não aceitassem o repatriamento ou não saíssem para outro país por sua conta, poderiam permanecer em Portugal, mas teriam de se sujeitar ao regime que o Governo lhes impusesse ${ }^{39}$.

Como se pode observar pelo exposto anteriormente, apesar dos esforços governamentais e da atuação das autoridades portuguesas para tentar impedir a entrada em Portugal de refugiados espanhóis, receando o regime, particularmente, a disseminação de ideias subversivas, estes indivíduos conseguiram penetrar no território português, contando para isso com ajuda não só de espanhóis já estabelecidos no país, como também de cidadãos portugueses, tanto civis como militares. São precisamente estas tentativas de vigilância e controlo da fronteira luso-espanhola e as ações das principais forças policiais portuguesas no terreno o assunto de que se ocupa o próximo capítulo.

\section{Vigilância de fronteira e operações policiais no norte do país}

Com o início da Guerra Civil em Espanha, a 18 de julho de 1936, diversas localidades portuguesas, próximas ou afastadas da fronteira, viram-se povoadas por espanhóis que procuravam refúgio dos horrores do conflito fratricida. Foram os casos de, por exemplo, Barrancos e Figueira da Foz. No entanto, estes refugiados passaram por muitas outras partes de Portugal, com particular incidência, naturalmente, para as povoações fronteiriças.

Existiam, em 1938, 22 pontos de passagem ao nível da fronteira terrestre portuguesa, que se estendiam de norte a sul do país: Caminha, Vila Nova de Cerveira, Valença, Monção, Peso (Melgaço), São Gregório, Vila Verde da Raia, Portelo, Quintanilha, Barca de Alva, Vilar Formoso, Segura, Beirã (Marvão), Galego, Campo Maior, Elvas (Caia e Estação), Mourão, Barrancos, Sobral da Adiça, Ficalho e Vila Real de Santo António ${ }^{40}$. Contudo, muito mais do que estes pontos de passagem fronteiriça em que havia presença policial, era toda a raia, seca ou molhada, não vigiada que preocupava e dava mais trabalho às autoridades portuguesas, sobretudo após o deflagrar da Guerra Civil de Espanha,

\footnotetext{
${ }^{39}$ Instituto Arquivos Nacionais/Torre do Tombo (Lisboa), Ministério do Interior, Gabinete do Ministro, Maço 481, pt. 8/10, Ofício do secretário geral do Ministério dos Negócios Estrangeiros para o Ministro do Interior, de 06/10/1936.

${ }^{40}$ Instituto Arquivos Nacionais/Torre do Tombo (Lisboa), Arquivo da PIDE/DGS, Direção dos Serviços de Estrangeiros e Fronteiras, Serviços Centrais, n. ${ }^{\text {9 } 9258, ~ R e l a t o ́ r i o ~ d a ~ P o l i ́ c i a ~ d e ~}$ Vigilância e Defesa do Estado (1932-1938).
} 
situação que levava a PVDE a afirmar, no já citado relatório, que «Não só a vigilância de fronteira absorvia uma grande parte do pessoal, como a que era preciso exercer-se internamente, esgotava o restante. $\rangle^{41}$.

Ressalve-se, no entanto, que logo após a vitória da Frente Popular nas eleições espanholas de fevereiro de 1936, vários espanhóis procuraram refúgio em Portugal por recearem os problemas que poderiam resultar dessa vitória eleitoral. Segundo o ofício do comandante geral da Guarda Nacional Republicana, General Augusto Manuel Farinha Beirão, para o ministro do Interior, todos estes indivíduos apresentavam-se legalmente documentados à entrada em Portugal ${ }^{42}$. Num outro documento, intitulado "Reflexões sobre a vigilância da fronteira", não assinado nem datado, o autor assume esta mesma preocupação com as graves consequências que poderiam advir das eleições em Espanha e com a necessidade de se vigiar a fronteira nacional. Este documento demonstra uma clara inquietação do Estado Novo relativamente à difusão de ideias comunistas em Portugal, assinalando também as dificuldades enfrentadas pela Guarda Fiscal no desempenho da principal função que lhe estava atribuída, a vigilância da fronteira. Assim, «Quase toda a gente desconhece os efetivos, os elementos de que ela dispõe para cumprir a sua missão normal (repressão dos delitos fiscais), e desconhece a orografia e hidrografia da fronteira que em largas extensões de terreno dificultam enormemente a sua missão normal e a missão eventual de vigilância [...] Não se pensa sequer nos seus efetivos limitados, na densidade de ocupação na linha fronteiriça (1 homem por quilómetro) e na incapacidade de muitos dos seus homens. $)^{43}$.

Esta ação de vigilância revelou-se difícil de concretizar. Como refere Maria da Conceição Ribeiro, «A vigilância das fronteiras depende, acima de tudo, do trabalho e da eficiência dos agentes colocados nas delegações e nos postos que constituíam as extensões regionais e locais da Secção Internacional da polícia política. [...] embora sucessivamente melhorada - quer quanto ao número de delegações e postos quer quanto ao seu apetrechamento técnico e humano - foi

${ }^{41}$ Instituto Arquivos Nacionais/Torre do Tombo (Lisboa), Arquivo da PIDE/DGS, Direção dos Serviços de Estrangeiros e Fronteiras, Serviços Centrais, n. ${ }^{\circ}$ 9258, Relatório da Polícia de Vigilância e Defesa do Estado (1932-1938).

${ }^{42}$ Instituto Arquivos Nacionais/Torre do Tombo (Lisboa), Ministério do Interior, Gabinete do Ministro, Maço 480, pt. 5/7, Ofício do Comandante Geral da GNR para o Ministro do Interior, de 26/02/1936.

${ }^{43}$ Instituto Arquivos Nacionais/Torre do Tombo (Lisboa), Arquivo Oliveira Salazar, CO/FI-25, pt. 1. Reflexões sobre a vigilância da fronteira. (Embora não se encontre datado, subentende-se, pelo conteúdo do documento, que data de inícios de 1936, nas vésperas das eleições espanholas de fevereiro de 1936). 
sempre relativamente reduzida [a rede da PVDE]. Como tal, a colaboração com outras polícias e, designadamente, no que concerne às fronteiras, com a Guarda Fiscal (mas também com a PSP e com a GNR) constituiu sempre um imperativo para a PVDE. $\rangle^{44}$. Esta necessidade de colaboração entre a PVDE e as restantes forças policiais portuguesas foi uma questão que não passou despercebida a Leone Santoro, chefe da Missão Italiana de Polícia que estudou a polícia portuguesa entre 1937 e 1940, precisamente durante o período em que ocorreram dois dos mais importantes conflitos europeus e mundiais do século XX e em que a manutenção da ordem interna era uma prioridade para Salazar.

Com efeito, Santoro salientava que «A vigilância sobre os estrangeiros é insuficiente, bem como a das fronteiras [...] sem que haja uma colaboração estreita e eficaz com outros órgãos, designadamente com a Guarda Fiscal. [...] A cooperação, a todos os níveis, entre as diversas polícias - PVDE, PSP, GNR, Polícia de Trânsito, Polícia Marítima, Guarda Fiscal - deveria, com benefício, ser reforçada. [...] Os agentes e os oficiais da PVDE mostram-se mal preparados para o exercício das suas funções, tornando-se indispensável a criação de escolas de polícia $[\ldots] .{ }^{45}{ }^{45}$.

No que concerne ao caso específico da Guerra Civil de Espanha, esta colaboração entre as diversas forças policiais portuguesas para vigilância da fronteira e repressão dos refugiados parece ter existido, logo desde o início do conflito. Uma das primeiras zonas do território nacional a ser procurado pelos fugitivos espanhóis foi a região norte, com particular destaque para os distritos de Viana do Castelo, Vila Real e Bragança, por a Galiza ter sido um dos primeiros espaços a ser fustigado pela revolta nacionalista. Se atentarmos ao já citado Registo Geral de Presos, verificamos que os primeiros espanhóis detidos pela PVDE após o despontar da guerra são oriundos de localidades situadas próximas da fronteira norte de Portugal, de que são exemplo Ourense, Requejo e Padornello, estas últimas duas pertencentes à região de Zamora. Condicionados pela localização geográfica, os habitantes destas e de outras regiões confinantes que procuravam escapar à guerra não tinham outra alternativa a não ser tentar entrar em Portugal, uma vez que do lado de Espanha estavam ameaçados pelas forças nacionalistas de Franco e do lado oposto encontravam-se perante a imensidão do oceano Atlântico, que lhes dificultava a fuga por esse caminho.

\footnotetext{
${ }^{44}$ Maria da Conceição Ribeiro, A Polícia Política ..., cit., p. 90.

${ }^{45}$ Relatório de Leone Santoro ao Ministério do Interior sobre os estudos feitos na PVDE pela Missão Italiana de polícia, citado por Maria da Conceição Ribeiro, A Polícia Política..., cit., p. 153-154.
} 
A vigilância da fronteira foi uma preocupação das autoridades portuguesas desde os primeiros momentos da guerra em Espanha. Logo nos primeiros dias imediatamente a seguir ao despontar do conflito foram produzidos relatórios que demonstravam esta preocupação e que permitem também conhecer a forma como estava disposto o serviço de vigilância.

Segundo o relatório assinado pelo Comandante do Batalhão 5 da GNR, coronel Luís José da Mota, a vigilância da fronteira localizada entre Vinhais (distrito de Bragança) e o rio Tejo, aproximadamente 450 quilómetros, estava a cargo de 14 postos, distribuídos entre a $4 .{ }^{\mathrm{a}}$, a $5 .{ }^{\mathrm{a}}$ e a $6 .{ }^{\mathrm{a}}$ Companhias ${ }^{46}$. Assim, a 4. ${ }^{\mathrm{a}}$ Companhia era responsável por 5 postos: Figueira de Castelo Rodrigo (12 praças), Almeida (12 praças), Vilar Formoso (13 praças), Souto (4 praças)

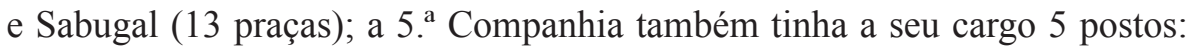
Penamacor (10 praças), Salvaterra do Extremo (8 praças), Zebreira (6 praças), Rosmaninhal (8 praças) e Malpica (8 praças); a $6 .{ }^{a}$ Companhia deveria garantir a vigilância da fronteira através de 4 postos: Vinhais (14 praças), Bragança (2 oficiais e 34 praças), Vimioso (8 praças) e Miranda do Douro (11 praças).

Com o intensificar do conflito em Espanha, reforçaram-se alguns destes postos, como Vinhais, Bragança, Figueira de Castelo Rodrigo, Almeida, Vilar Formoso, Salvaterra do Extremo, Rosmaninhal e Malpica, apresentando-se como principais justificações para o mesmo o facto de o terreno ser, por vezes, demasiado acidentado e a grande área que estes postos tinham de cobrir, o que dificultava o trabalho dos operacionais. Pelo exposto no citado relatório, observa-se que não era dada particular atenção às zonas dos rios que, pelas suas características naturais, se consideravam serem inacessíveis, como se verificou no caso dos rios Douro e Tejo. Um dos principais aspetos a salientar sobre este relatório é a preocupação em reforçar a ideia de que existia um bom entendimento e constante comunicação entre as diversas autoridades que operavam no terreno, nomeadamente a GNR, a Guarda Fiscal e o Comando Militar de Bragança, responsável pelo serviço de vigilância naquela zona.

Ainda de acordo com o relatório do coronel Luís José da Mota, entendia-se não ser necessário reforçar os postos fronteiriços que confinavam com regiões espanholas que se encontravam em poder dos nacionalistas por se entender que nestas reinava a ordem. Sobre os refugiados que então entravam em Portugal pelas regiões onde se encontravam estes postos, refere-se que estes eram

${ }^{46}$ Instituto Arquivos Nacionais/Torre do Tombo (Lisboa), Ministério do Interior, Gabinete do Ministro, Maço 481, pt. 35/18, Relatório do Comandante do Batalhão 5 da GNR, Coronel Luís José da Mota, de 13/08/1936. (Embora o relatório date de agosto de 1936, o seu conteúdo respeita ao que se verificava em julho desse mesmo ano). 
maioritariamente mulheres e crianças, destacando-se a entrada de dois oficiais generais, um comandante e nove civis fiéis aos republicanos no posto de Vinhais. Comprovando a prática comum que se verificou ao longo de toda a guerra civil, os militares foram entregues no comando militar, neste caso de Bragança, e os civis ao Delegado da Polícia Internacional destacado para aquela zona.

Um outro relatório, elaborado pelo comandante do Batalhão 3 da GNR, coronel João Rodrigues Batista, em julho de 1936, permite conhecer a distribuição dos postos de vigilância localizados mais a sul de Portugal $^{47}$. À 4. ${ }^{a}$ Companhia estavam atribuídos 8 postos: Nisa (1 oficial e 14 praças), Castelo de Vide (7 praças), Marvão (5 praças), Portagem (8 praças), Alegrete (4 praças), Arronches (7 praças), Campo Maior (13 praças) e Elvas (1 oficial

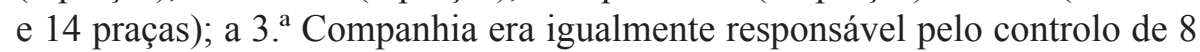
postos: São Brás ( 9 praças), Mocissos (6 praças), Beatas (6 praças), Defesas ( 9 praças), Moinho do Gato (2 praças), Herdade da Abegoaria (7 praças), Herdade da Ameada (8 praças) e Herdade da Galiana (7 praças); a 2. ${ }^{a}$ Companhia era responsável também por 8 postos: Barrancos (10 praças), Sobral da Adiça (1 furriel e 10 praças), Vila Verde de Ficalho (1 oficial e 17 praças), Crespo (2 praças), Valcovo (2 praças), São Marcos (2 praças), M. de São Domingos (1 oficial e 13 praças) e Pomarão (6 praças); por seu turno, à 5. ${ }^{a}$ Companhia cabia a vigilância de 5 postos: Almada de Ouro (4 praças), Foz de Odeleite (4 praças), Vila Real de Santo António (6 praças), Castro Marim (10 praças) e Alcoutim (11 praças).

Neste relatório considera-se que, apesar dos fracos efetivos, a Guarda Fiscal e a Guarda Nacional Republicana eram suficientes para vigiar e controlar toda a fronteira terrestre, assinalando-se também, tal como no relatório anterior, que a entrada de refugiados em Portugal era muito pouco significativa. $\mathrm{O}$ autor do relatório defende ainda que a entrada reduzida de comunistas se devia ao facto de estes não sentirem um ambiente favorável em Portugal e que a pouca presença de indivíduos de direita se justifica pela vigilância que lhes era feita pelos comunistas.

As fontes consultadas fazem referência particularmente a refugiados comunistas e simpatizantes da Frente Popular, o que nos leva a colocar algumas interrogações relativamente à escassa referência a refugiados nacionalistas. A PVDE não os perseguia porque não os considerava uma ameaça devido a serem defensores de um tipo de governo próximo daquele que vigorava

\footnotetext{
${ }^{47}$ Instituto Arquivos Nacionais/Torre do Tombo (Lisboa), Ministério do Interior, Gabinete do Ministro, Maço 481, pt. 35/18, Relatório do Comandante do Batalhão 3 da GNR, Coronel João Rodrigues Batista, de julho de 1936.
} 
em Portugal? Devido ao facto de a fronteira ter sido rapidamente dominada pelos nacionalistas, os seus simpatizantes não tinham razões para entrar em Portugal? Estas questões parecem ter uma resposta positiva, uma vez que, tal como adianta César Oliveira, assim que se provasse que eram afetos à ideologia nacionalista, eram libertados e facilmente podiam dirigir-se para qualquer zona controlada pelas tropas de Franco ${ }^{48}$. Sobre este tema, e referindo-se à zona de Barrancos, João Urbano Pires salienta que no início do conflito, numa altura em que a fronteira não estava ainda controlada pelos franquistas, mas sim pelos «vermelhos», eram os nacionalistas quem procurava refúgio em Portugal ${ }^{49}$.

A vigilância da fronteira luso-espanhola não era repartida apenas entre a Guarda Nacional Republicana e a Guarda Fiscal, havendo também a colaboração com a Polícia de Segurança Pública. A 15 de agosto, o major de Cavalaria Aníbal Franco, Comandante do Batalhão 4 da GNR, dava conta que o serviço de vigilância no posto de Valença, a cargo da 5. Companhia, era feito em colaboração com a Guarda Fiscal e com os agentes da PSP que tinham sido destacados para aquela zona da fronteira ${ }^{50}$. Para além do posto de Valença, a 5. ${ }^{a}$ Companhia era ainda responsável pelos postos de Monção e de Caminha, ao passo que a $6 .{ }^{\text {a }}$ Companhia estava encarregue dos postos de Chaves e de Montalegre. À semelhança do que considerou o coronel Luís José da Mota, também o major Aníbal Franco entendia que, devido ao facto de toda a fronteira norte estar em poder dos nacionalistas, a ordem estava garantida nessa zona. Assim, mandou-se retirar a Companhia que havia sido destacada para Valença.

Apesar do estabelecimento de todos estes postos de vigilância e da colaboração direta existente entre as diversas forças policiais, a entrada de refugiados espanhóis foi constante, sobretudo durante os meses iniciais do conflito espanhol, com particular destaque para o distrito de Bragança. Disso mesmo dava conta o governador civil desse distrito, Salvador Nunes Teixeira, ao ministro do Interior em vários relatórios e telegramas. Assim, ao longo destes primeiros meses o governador civil de Bragança assinalava a entrada em Portugal de foragidos espanhóis, tanto civis como militares.

A 26 de julho de 1936, Salvador Nunes Teixeira comunicava ao ministro do Interior a entrada pelo posto da Guarda Fiscal de Moimenta (concelho de Vinhais) de três generais governamentais e nove civis, desarmados, que foram

\footnotetext{
${ }^{48}$ César Oliveira, Salazar..., cit., p. 156.

${ }^{49}$ João Urbano Pires, A memória da Guerra Civil de Espanha ..., cit., p. 145.

${ }^{50}$ Instituto Arquivos Nacionais/Torre do Tombo (Lisboa), Ministério do Interior, Gabinete do Ministro, Maço 481, pt. 35/26, Relatório do Comandante do Batalhão 4 da GNR, Major Aníbal Franco, de 15 de agosto de 1936.
} 
entregues ao administrador do concelho de Vinhais que, por sua vez, os fez chegar à Polícia Internacional ${ }^{51}$. No final do mês seguinte, este governador civil continuava a relatar as detenções de refugiados espanhóis que procuravam entrar no país, como por exemplo, a que ocorreu a 28 de agosto. Neste dia, dois civis espanhóis residentes em Zamora foram capturados pela Guarda Fiscal instalada em Deilão (concelho de Bragança), alegando que procuravam refugiar-se em Portugal por recearem ser fuzilados, algo que viram acontecer a alguns dos seus vizinhos. Estando desarmados, foram também entregues à Polícia Internacional ${ }^{52}$. A 16 de setembro de 1936, já depois de mais de mil refugiados terem sido repatriados para Tarragona, o governador civil de Bragança, registou a captura de mais dois civis espanhóis no posto de Deilão, os quais, afirmando não terem qualquer fação política, procuravam esconder-se no país por estarem a ser perseguidos pelos fascistas. Consta ainda deste ofício o relato de um episódio que comprova a existência de solidariedades locais na fronteira luso-espanhola durante a guerra de 1936-1939, bem como os perigos que os habitantes locais corriam por se relacionarem com os refugiados espanhóis. A 12 de setembro, os falangistas detiveram os portugueses Francisco Pedro Martins e Basílio Augusto, residentes em Vinhais, suspeitando-se que o primeiro dera guarida a um refugiado e que o segundo levava uma carta para um foragido espanhol. No entanto, acabaram por sair em liberdade passados dois dias ${ }^{53}$.

Também o general Augusto Manuel Farinha Beirão ia comunicando ao ministro do Interior a situação na fronteira portuguesa. Assim, a 27 de julho de 1936, este oficial chamava a atenção para a detenção de doze espanhóis no concelho de Vinhais, dos quais dois eram generais e um era comandante ${ }^{54}$. Passados dois meses, a 29 de setembro, Augusto Farinha Beirão assinalava que a situação na fronteira parecia estar mais calma, destacando que não se registava

${ }^{51}$ Instituto Arquivos Nacionais/Torre do Tombo (Lisboa), Ministério do Interior, Gabinete do Ministro, Maço 481, pt. 35/10, Telegrama de Salvador Nunes Teixeira para o ministro do Interior, de 26 de julho de 1936.

${ }^{52}$ Instituto Arquivos Nacionais/Torre do Tombo (Lisboa), Ministério do Interior, Gabinete do Ministro, Maço 479, pt. 28/2, Relatório de Salvador Nunes Teixeira para o ministro do Interior, de 29 de agosto de 1936.

${ }^{53}$ Instituto Arquivos Nacionais/Torre do Tombo (Lisboa), Ministério do Interior, Gabinete do Ministro, Maço 479, pt. 8/9, Ofício de Salvador Nunes Teixeira para o ministro do Interior, de 16 de setembro de 1936 .

${ }^{54}$ Instituto Arquivos Nacionais/Torre do Tombo (Lisboa), Ministério do Interior, Gabinete do Ministro, Maço 481, pt. 35/9, Telegrama do General Augusto Manuel Farinha Beirão para o ministro do Interior, de 27 de julho de 1936. 
a presença de refugiados na fronteira que compreendia os distritos de Viana do Castelo e Vila Real, exceção feita a Melgaço e a Peso ${ }^{55}$.

No distrito de Viana do Castelo a situação apresentava-se mais complicada, sendo constantes os pedidos e as ações de reforço dos postos fronteiriços de vigilância. A 31 de julho de 1936, o Comandante da PSP de Viana do Castelo, Tenente Francisco Pimenta da Gama, comunicava ao comando geral que, em consequência do grande movimento de pessoas na fronteira, resultante do ataque franquista à cidade de Tuy, havia deslocado vinte e dois guardas e um graduado para reforçar os postos fronteiriços da Polícia Internacional e da Guarda Fiscal ${ }^{56}$. Já o governador civil desse distrito, Tomás Fragoso, requeria ao ministro do Interior que fosse reforçado o posto da GNR de Melgaço devido ao facto de se ter registado a entrada por Castro Laboreiro de espanhóis armados que procuravam localizar os adversários políticos que se tinham refugiado em Portugal ${ }^{57}$.

Esta região parece ter sido uma das mais complicadas de vigiar, sobretudo devido ao terreno acidentado e montanhoso. Em finais de agosto de 1936, foi nomeada uma patrulha com a particular missão de investigar se as casas dos habitantes de Castro Laboreiro estavam a ser alvo de buscas por parte de espanhóis armados, concluindo-se que estes eventualmente teriam entrado em Portugal perseguindo algum fugitivo e não para alterar a ordem pública por meio de buscas domiciliárias e ameaças ${ }^{58}$. Segundo este ofício, foram detidos, na mesma altura, quatro cidadãos que estavam escondidos na região de Castro Laboreiro e o chefe da Polícia Internacional de São Gregório multou os portugueses que tinham acolhido os refugiados, considerando que o fizeram por amizade e não por identificação política.

Para colmatar as dificuldades existentes nesta zona, a PVDE considerava que a reduzida fiscalização dos postos, geralmente levada a cabo por apenas três praças, só melhoraria com um forte reforço, dada a grande extensão da área, e

${ }^{55}$ Instituto Arquivos Nacionais/Torre do Tombo (Lisboa), Ministério do Interior, Gabinete do Ministro, Maço 481, pt. 35/36, Ofício do General Augusto Manuel Farinha Beirão para o ministro do Interior, de 29 de setembro de 1936.

${ }^{56}$ Instituto Arquivos Nacionais/Torre do Tombo (Lisboa), Ministério do Interior, Gabinete do Ministro, Maço 481, pt. 35/16, Ofício do Comandante da PSP de Viana do Castelo para o comando geral, de 31 de julho de 1936.

${ }^{57}$ Instituto Arquivos Nacionais/Torre do Tombo (Lisboa), Ministério do Interior, Gabinete do Ministro, Maço 481, pt. 35/32, Ofício do Comandante da PSP de Viana do Castelo para o comando geral, de 25 de agosto de 1936.

${ }^{58}$ Instituto Arquivos Nacionais/Torre do Tombo (Lisboa), Ministério do Interior, Gabinete do Ministro, Maço 481, pt. 26/1, Ofício do Comandante Aníbal Franco para o ministro do Interior, de 5 de setembro de 1936. 
que o destacamento de praças da GNR deveria ser deslocado de São Gregório para Castro Laboreiro de forma a garantir uma fiscalização mais eficaz ${ }^{59}$.

Também o distrito de Braga foi procurado pelos refugiados como ponto de entrada em Portugal. Sobre esta situação, o Comandante do Batalhão 4 da GNR dava conta da entrada de espanhóis pela fronteira de Portela do Homem, alguns dos quais eram responsáveis pela propaganda comunista na aldeia de Covide, pelo que pedia o envio de agentes para essa localidade. Em resposta, o comandante geral da GNR informava sobre o destacamento de um furriel e catorze praças para estabelecer um posto de vigilância nessa zona ${ }^{60}$.

Com o decorrer dos meses, a situação na fronteira luso-espanhola acalmou. Esta parece ter sido uma realidade particularmente notória a partir de finais de outubro 1936, o que não significa, contudo, que não continuassem a entrar refugiados em Portugal. Foram vários os ofícios do comandante geral da GNR para o ministro do Interior pedindo que fossem retirados os reforços de alguns postos fronteiriços, como Guarda, Castelo Branco, Bragança e Vinhais, ou que fossem reduzidos os efetivos, como se verificou no caso dos postos sedeados no distrito de Viana do Castelo. Como justificação para estes requerimentos, Augusto Farinha Beirão salientava ter sido informado de que nada se passava nas localidades espanholas fronteiriças, em virtude de estarem já controladas pelos nacionalistas ${ }^{61}$.

Observou-se a partir do início da guerra civil em Espanha uma clara preocupação do regime português em reforçar os postos de vigilância fronteiriços, receando a entrada massiva de espanhóis que poderiam implementar ideias consideradas subversivas pelo Estado Novo, sobretudo no que dizia respeito aos comunistas, os chamados «refugiados vermelhos». Para tal, existiu uma colaboração próxima entre as várias forças policiais nacionais, PVDE, GNR, PSP e Guarda Fiscal. Contudo, este reforço policial e a maior preocupação com a vigilância da fronteira, mais evidentes nos primeiros meses do conflito espanhol, diminuindo de intensidade com o passar do tempo, foram impotentes para evitar a entrada de inúmeros refugiados em Portugal.

\footnotetext{
${ }^{59}$ Instituto Arquivos Nacionais/Torre do Tombo (Lisboa), Ministério do Interior, Gabinete do Ministro, Maço 481, pt. 8/3, Ofício do secretário geral da PVDE para o ministro do Interior, de 7 de setembro de 1936 .

${ }^{60}$ Instituto Arquivos Nacionais/Torre do Tombo (Lisboa), Ministério do Interior, Gabinete do Ministro, Maço 482, pt. 3/8, Ofício do Comandante Geral da GNR para o ministro do Interior, de 22 de agosto de 1936.

${ }^{61}$ Instituto Arquivos Nacionais/Torre do Tombo (Lisboa), Ministério do Interior, Gabinete do Ministro, Maço 480, pt. 5/74; pt. 5/86; pt. 5/95, Ofícios do Comandante Geral da GNR para o ministro do Interior, de 10 de novembro, 30 de outubro e 17 de outubro de 1936 , respetivamente.
} 


\section{Conclusão}

Dada a sua condição de país confinante, Portugal foi procurado como lugar de refúgio por muitos espanhóis que pretendiam escapar à guerra civil. Apesar das esperadas dificuldades que estes foragidos encontraram no país, tendo em consideração a natureza do regime salazarista, fechado e receoso do contacto com o exterior, e o seu estatuto colaboracionista com os nacionalistas de Franco, os espanhóis puderam comprovar a solidariedade e a humanidade do povo português da raia que, desafiando as ordens de Salazar e arriscando ser punidos, como de resto aconteceu em alguns casos, não deixou de lhes prestar auxílio. Ressalve-se que este espírito solidário atingiu não só civis, como também militares.

Antes do início da guerra em Espanha, muitos espanhóis procuravam Portugal por veraneio, lazer e razões económicas, situação que se alterou a partir de 1936, registando-se um decréscimo acentuado desse número, passando a vir essencialmente refugiados.

Com o despontar do conflito espanhol cresceram as preocupações do Estado Novo relativamente à vigilância da fronteira terrestre com Espanha, receando Salazar o contacto da população portuguesa com os «refugiados vermelhos». Neste sentido, muitos postos fronteiriços foram reforçados com efetivos de várias forças policiais, registando-se também um acentuado aumento de operações no terreno, procurando-se localizar os foragidos que se internavam em Portugal, que contou com uma estreita colaboração entre as diversas autoridades.

Não obstante esta conjugação de esforços, durante o período que durou a guerra civil espanhola, sobretudo nos primeiros meses, o território português viu-se ocupado por indivíduos que procuravam a todo o custo escapar aos horrores do conflito e às perseguições dos nacionalistas. Não sendo possível quantificar com exatidão o número de espanhóis que procuraram abrigo em Portugal, sabe-se que este rondou, no mínimo, os 1.500, visto haver registo do repatriamento de 1.445 indivíduos para Tarragona a 10 de outubro de 1936. Para além destes, vários foragidos foram entregues pela polícia aos franquistas, ao passo que outros tiveram melhor sorte e, sendo ajudados por portugueses ou por espanhóis já residentes no país, acabaram por conseguir escapar à perseguição e fixar-se em Portugal. É de destacar o facto de muitos refugiados, sobretudo os pertencentes à Frente Popular, ou pelo menos os que temiam a perseguição dos franquistas, para além dos que simplesmente fugiam da guerra, terem arriscado procurado entrar num país onde o regime instaurado era simpatizante das ideias nacionalistas. 